\title{
The effect of phonological awareness on rapid automatized naming
}

\author{
Mahdi Khodadoust ${ }^{1,2}$, Reyhane Mohamadi*1, Leila Janani ${ }^{3}$, Zakiye Javadi ${ }^{4}$, Amir Sadeghi $^{5}$ \\ Received: 10 Apr 2017 \\ Published: 18 Apr 2019
}

\begin{abstract}
Background: Phonological awareness (PA) is a fundamental predictor of reading disability. However, researches on reading have indicated that PA assessment alone is not sufficient to prevent reading problems. Rapid automatized naming (RAN) has been suggested as another influential factor in reading deficits independent of PA. This study investigated the impact of phonological awareness on rapid automatized naming.

Methods: This was a randomized clinical trial study in which 62 Persian monolingual first graders were recruited from 3 schools using convenience sampling. Inclusion criteria were lack of deficits with sensory-motor skills and knowledge of the Persian alphabets. Measures of PA and RAN were utilized. The participants were randomly assigned into either the intervention or the control group. The intervention group was divided into small groups of 4-6 children who received thirty 40-minute training sessions in PA. T test, MannWhitney, and Wilcoxon tests were used for data analysis.

Results: The results revealed that the RAN time was significantly reduced ( $\mathrm{p} \leq 0.001$ ), with a significant increase in PA scores $(\mathrm{p} \leq 0.001)$. In addition, there was a significant inverse relationship between some of the measures of the phonological awareness subtests and rapid automatized naming (eg, phonemic blending \& RAN (numbers): $\rho=-0.52$ with $\mathrm{p} \leq 0.001$ ).

Conclusion: The findings showed that in the initial assessment, PA and RAN had a significant relationship, but RAN could be significantly improved by PA training.
\end{abstract}

Keywords: Rapid automatized naming, Phonological awareness, Reading, Predictors of reading, Double-deficit hypothesis

Conflicts of Interest: None declared

Funding: Iran University of Medical Sciences

\section{*This work has been published under CC BY-NC-SA 1.0 license. \\ Copyright $₫$ Iran University of Medical Sciences}

Cite this article as: Khodadoust M, Mohamadi R, Janani L, Javadi Z, Sadeghi A. The effect of phonological awareness on rapid automatized naming. Med J Islam Repub Iran. 2019 (18 Apr);33:32. https://doi.org/10.47176/mjiri.33.32

\section{Introduction}

Literacy skills (ie, reading, writing) are prerequisite for success in social and academic life. Although all children are assumed to acquire such skills at school, some face problems (1). Global reports indicate a 3.5\%-10\% prevalence of dyslexia (2-4), the problem that has been suggest-

Corresponding author: Dr Reyhane Mohamadi, mohamadi.r@iums.ac.ir

1. School of Rehabilitation, Iran University of Medical Sciences, Tehran, Iran

2. Neuroscience Research Center, Institute of Neuropharmacology, Kerman University of Medical Sciences, Kerman, Iran

3. Department of Biostatistics, School of Public Health, Iran University of Medical Sciences, Tehran, Iran

4. School of Paramedical Sciences, Mashhad University of Medical Sciences, Tehran, Iran

5. School of Teacher Education, University of Canterbury, New Zealand ed to be caused by weaknesses in cognitive, emotional, social, and educational factors $(5,6)$. Several scholars have tried to identify early predictors of educational attainment at primary school levels by studying young children during preschool period $(7,8)$. These researches may

$\uparrow$ What is "already known" in this topic:

Nowadays, there is less disagreement on this notion that students with reading disorder, in general, and dyslexia, in particular, may have a fundamental deficit in their phonological awareness since such awareness is unanimously known as a strong predictor of reading ability and reading disorder.

\section{$\rightarrow$ What this article adds:}

There are many debates about the relationships between phonological awareness and rapid automatized naming in prediction of dyslexia. This study showed the positive effect of phonological awareness intervention on rapid automatized naming. However, the findings of this study contradicted the double-deficit hypothesis. 
help prevent academic failure, loss of self-confidence, and weakening children's incentives in primary school age range (9).

Phonological awareness as the core predictor of reading (10-12) has been the most common purpose of researches done on reading and writing (13). However, despite stabilized significance of phonological awareness as the most important predictive component, merely strengthening it does not seem to guarantee prevention of reading and writing disorders (14). In 1999, Wolf and Bower suggested deficits in rapid automatized naming (RAN) as the second core of reading deficit (15). However, since decades ago, there has been disagreement on how RAN may affect dyslexia. A common view among researchers suggests that RAN is a subset of phonological awareness. As an example, Wagner and Torgesen (11) consider RAN as a manifestation of the ability to "represent phonological codes from long-term memory" (16) or "phonological recoding in lexical access"(11-15). Contrary to this view, cognitive neuroscience researchers (eg, Meyer and Wolf) argue that phonological awareness should be seen as an independent source of impairment in dyslexia (17-20).

Therefore, it is vital to further investigate the relationship between phonological awareness and RAN for effective diagnosis, prediction, and treatment of developmental reading disorders. In other words, if we accept that rapid naming is the subset of phonological awareness, the majority of individuals with reading disability may improve their RAN through emphasizing phonological awareness. If we agree to take RAN and phonological awareness as independent and equally important in reading process, subgroups with single-source deficit in either skills or double-source deficit can be assumed (15). Moreover, double-deficit hypothesis proposed by Wolf and Bower holds the argument that deficits in the underlying processes of phonological awareness and RAN are 2 independent sources of reading disability with simultaneous presence of deficits in the 2 skills leading to a serious reading disorder (15).

Jou Schatschneider et al found that low reading performance due to rapid naming deficits could be hardly considered independent of phonological deficits (21). In contrast, Chiappe et al stated that phonological awareness was the only core deficit of dyslexia and that rapid naming and phonological awareness should not be considered as independent (22).

To further investigate, Wolf and Bower defended their theory in 2 studies on primary school children. They argued for the presence of 3 subgroups, including those with deficits in rapid naming, deficits in phonological awareness, and double deficits (deficits in both PA and RAN) $(17,23)$.

In 2014, comparing 205 students (second to sixth graders), Heikkilä et al found that according to the doubledeficit hypothesis, prevalence and severity of reading disability were greatest in the double-deficit group (24).

In a part of their article published in 2006, Vukovic and Siegel reviewed the evidence from studies in response to the following question: Should naming speed be characterized independently from phonological awareness? (14).
They argued that although it is evident that rapid naming plays a key role in determining the variance of reading ability, independent of phonological awareness, it is difficult to disentangle the effect of rapid naming from that of phonological processing. The results of studies investigating the double-deficit hypothesis also suggest that naming speed is significantly correlated with phonological measures. Findings from other studies, however, have indicated that naming speed and phonological processing have a high proportion of shared variance. Other studies have suggested that RAN may be an indicator of global processing speed.

Although rapid naming may represent the ability to rapidly retrieve information from long-term memory, its relationship with dyslexia may lie specifically in the ability to rapidly retrieve phonological codes, which would still make it useful to classify RAN as a phonological task (16).

Since the effectiveness of dyslexia treatments is moderate $(0.07$ to 0.56$)$, as reported by meta-analysis studies $(25,26)$, it seems that researches unanimously believe that early diagnosis and intervention for children at risk may increase the effectiveness of the therapy (27). This requires an accurate understanding of predictors of reading and reading disorders.

The results of clinical interventions also argue for having a direct impact on theoretical knowledge. However, the contradiction between the results of the published studies in this regard is also an issue that leads us to ponder more about the heterogeneity of these defects $(14,28)$.

Since various studies have provided conflicting and heterogeneous results about the relationship between phonological awareness and naming speed as the 2 important and key predictors of reading, this study was designed to provide further evidence to clarify the issue.

\section{Methods}

\section{Participants}

The initial sample was obtained by convenience sampling method from 3 private schools that followed the Iranian national curriculum. Based on the school results, the participating children seemed to be doing well with a high rank achievement. The children were randomly assigned into control and intervention groups. As the level of phonological awareness is affected by alphabetic knowledge of children, one of the criteria to participate in the study was that the score of alphabetic knowledge should not be more or less than 2 standard deviations from the mean $($ mean $\pm 2 S D=32 \pm 71)$. In summary, inclusion criteria were as follow: children aged 5.5-6.5 years, approval of the preschool general screening (the government requirement for school entry which is believed to identify children with no difficulties), monolingual children, children's average score in the alphabetic knowledge test (pretest), with scores no more or less than 2 standard deviations below the mean score.

All participants were selected from a relatively similar socioeconomic background considering such factors as parents' occupation and educational level, types of preschool (private, public), and training rate of alphabet 
knowledge.

All first graders from 3 schools $(\mathrm{N}=120)$ who met the criteria mentioned above were initially invited to participate in the study, and those whose parents gave consents $(\mathrm{N}=95)$ took an alphabetic knowledge test and completed the demographic questionnaire. A total of 33 children who were identified to have epilepsy, convulsion, brain injury, psychiatric disorders (eg, autism, etc. diagnosed by a psychiatrist), intellectual disability, and those who took specific training courses related to the measures of the current study were excluded. This led to recruitment of 62 children who were assigned into control and experimental group. Figure 1 presents the sampling procedure.

\section{Intervention}

All children in the intervention group received codeoriented training of phonological awareness and alphabet knowledge for 5 consecutive weeks. Every week, three 45-minute training sessions were offered to 4-6-year-old children, so each child received a total of 22.5 hours of code-focused training. The control group did not receive any intervention during this period.

Due to the importance of simultaneous teaching of alphabetic knowledge and phonological awareness, those

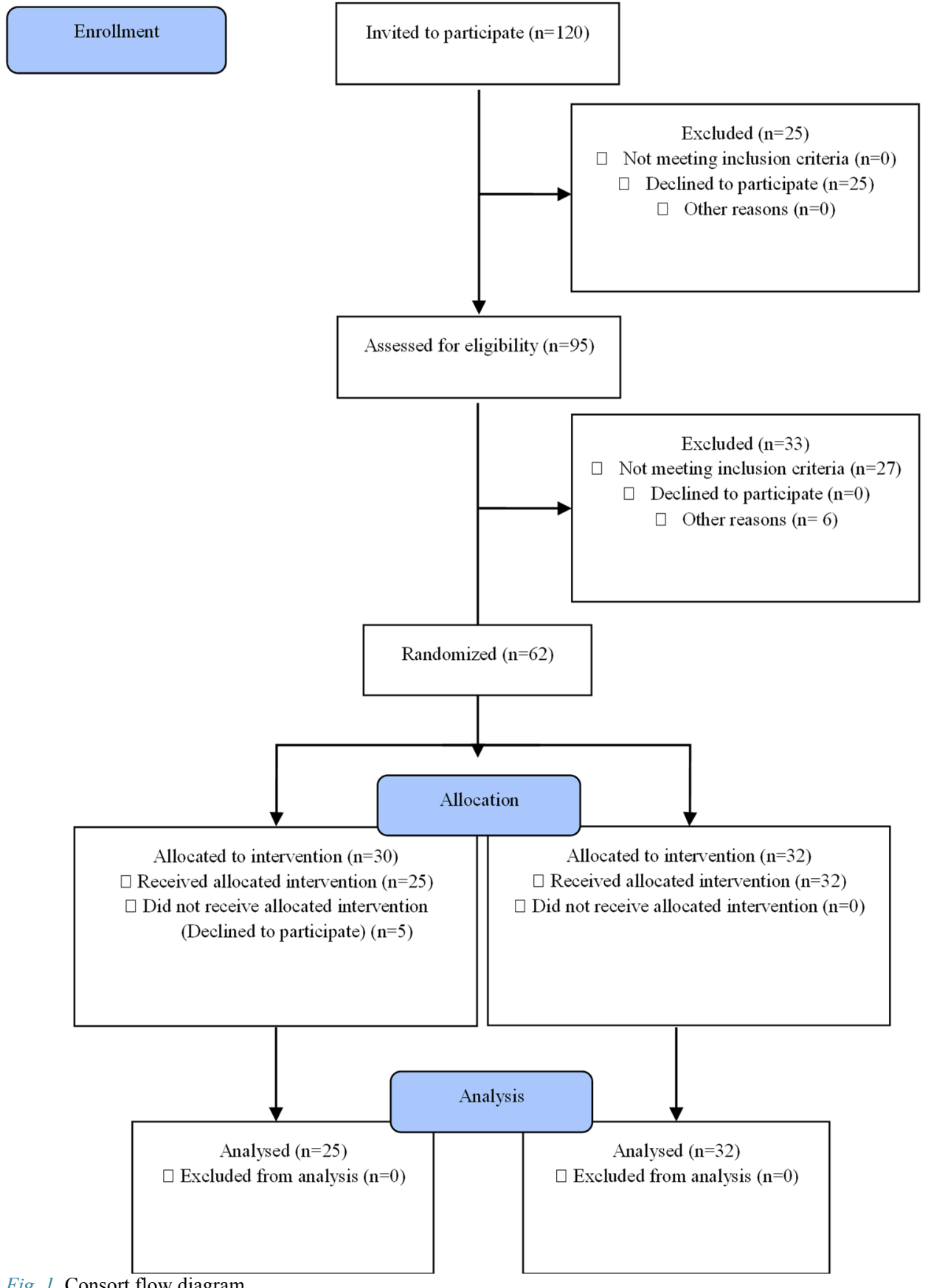


performing the intervention in this study were 4 experienced first grade teachers. Before the intervention, the teachers received explanations on the objectives and practiced through role-plays during four 2-hour sessions. The training approach of phonological awareness was derived from the intervention performed in Farabi et al (30), and the order for practicing letters was designed according to first grade textbook (letters used in training courses of lessons 1 to 10 of Let's Read). Based on the textbook and curriculum, those letters that the children were supposed to learn on their school days during our intervention were excluded to prevent the data from any contamination. Considerations were given to selection criteria for the letters to be taught in our intervention plan, which included factors of simple spelling, order based on the curriculum, simplicity in teaching, and high frequency and preceding in the process of production growth (31). Therefore, 12 phonemes, including 4 vowels and 8 consonants were selected for training. The instructor first introduced the sounds of the letters to children and then showed their spelling to them. The goals of the 5-week intervention sessions were as follow (30):

- Week 1: Practices on introduction to words (in a text, the child is asked to raise his hand each time he hears the name of an object, and...) + syllabic exercises (finding a meaningful syllable in a word, etc.) + inter-syllabic exercises (finding the words with similar rhyme and alliteration) + teaching the shape and sound of the letter "II"(p)

- Week 2: Exercises aimed to identify syllables: Deleting the first and last syllables + phonological combination: in the one syllable words + teaching the shapes and

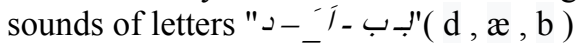

- Week 3: Phonological combination: In 1 and 2 syllable words + phonemic exercises: identifying in the beginning of the word + teaching the shapes and sounds of let-

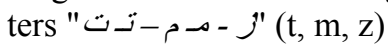

- Week 4: Phonological exercises: identifying at the end of the word and deleting at the beginning and end of the word + teaching the shapes and sounds of letters " ش-" (

- Week 5: Phonological exercises: Identifying and deleting at the beginning and end of the word + teaching the

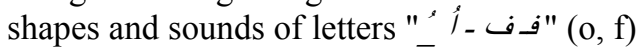

\section{Measures}

All participants were required to take phonological awareness, naming speed, alphabetic knowledge, and word decoding tests before and immediately after training sessions. Participants were also given a demographic questionnaire.

\section{Demographic or individual information questionnaire}

This questionnaire consisted of 3 sections and included questions about personal and family information and medical and communication status of children.

\section{Phonological awareness test}

This test consisted of 3 parts and each targeted syllabic awareness, awareness of inter-syllabic units (alliteration and rhyme), and phonemic awareness in some subtests.
The subtests of alliteration recognition, rhyme recognition, phonemic blending, recognizing words with the same initial phonemes, words with the same final phonemes, naming final phonemes, and deleting final phonemes were used (32). In the subtests of alliteration and rhyme recognition, participants were required to identify 2 images from 3 given images that had alliteration or rhyme. In phonemic blending subtest, children were required to name the syllables of the given image first followed by saying the complete word. In the subtests of identification of words with the same initial and final phonemes, the participants were asked to first name the 3 given images and then pointed the 2 images with the same initial or final phonemes. In the subtest of naming and deleting the final phonemes, children named the given image followed by saying its final phoneme. In the deleting the final phonemes task, they were required to say the word without the final phoneme.

For all tests, a trained examiner used examples to clarify for the children what they were expected to perform to ensure that the participants understood the test requirement. For the unknown words (images), the examiner named the item for children and asked them to repeat it for a few times before testing. The maximum score for each subtest (six subtests) was 10 .

\section{Rapid automatized naming}

This test was modelled on those developed by Denckla and Rudel (33) who have been repeatedly referred to in similar studies $(34,43)$. The subtests of this measure included naming letters, digits, and images (35). Soleimani et al reported the validity and reliability of the test. Experts in the field also ascertained the validity of the test content and its suitability for rapid naming. The test reliability was calculated by test-retest method by running the test twice, with an interval of 2 weeks on the same sample, and comparison of means and correlation coefficients were computed from the 2 stages of conducting the tests (36). While performing, the participants were required to name all 50 items, which were all images and numbers, presented on the 4 test cards loudly and as quickly as they could. To ensure that children were familiar with test items, before presenting any cards, the child was required to name the items once as a trial practice. If a child named an item incorrectly, the correct word was uttered for him. Once the child was ensured to know the items, the test was administered. The time it took for the child to name the test items was recorded in seconds (36) and used as the scores for the rapid automatized naming test where lower values indicated higher rapid naming ability.

\section{Alphabetic knowledge: Diagnostic reading test}

The purpose of the alphabetic knowledge test (recognition of letters, shapes, sound-letter correspondences) was to determine the extent to which the child could both recognize letters and pronounce their corresponding sounds and find the letter or relevant letters in a series of letters after hearing the sound of a particular letter. In the subtest, children were required to pronounce the sound of a given letter and pronounce the sounds of the letters which ap- 
peared in small and large fonts. In the subtest of letter recognition, they were required to identify the letter that was uttered by the examiner from a series of letters (3738).

\section{Word decoding}

In this task, 30 high-frequency words suitable for the first graders were used to measure word decoding. Highly frequent words were extracted from the Basic Vocabulary Book (39) that reported the results from a national study on the frequency of words for primary school age children in Iran. A booklet was produced containing the selected words written in B Mitra font size 16, with each word appearing on 1 page. The test contained 15 words with phonemes that were to be used in the practice trails, and 15 words with various phonemes (ie, phonemes from the practice trails and non-targeted phonemes). In this test, the examiner displayed each word to children and asked them to read it out laud as part of a bigger study.

\section{Sample size}

The sample size was determined using the $G^{*}$ Power3 software. Considering the big effect size (0.8) in Cohen's sample size, 62 children were recruited (actual power $=$ 0.80). Participants were assigned into the intervention or the control group by randomized quadripartite blocks. Thirty participants were in the intervention group and 32 in the control group. Five children were excluded from the intervention group due to lack of children's cooperation, lack of parents' willingness to continue, or being absent more than 2 consecutive sessions during the intervention. In other words, 26 children out of 30 , with the drop-out rate of $15 \%$, performed all measures in the intervention group.

\section{Procedure}

After obtaining ethical approval from Iran University of Medical Sciences, invitations of participation, consent forms, and the demographic questionnaire were sent to the parents.

Following the selection process, children were randomly assigned into intervention and control groups. For anonymity purposes, unique codes were used for each participating child. The corresponding codes were generated by software and sealed envelopes were used to ensure randomization process. In addition, the examiners were not involved in the selection process.

The duration of each assessment session was approximately 60 minutes and was implemented in 2 separate sessions on the same day, if needed. All tests were conducted at school. The examiners were 3 speech therapists who had received 6 hours of training and briefing sessions to ensure all examiners use an identical approach to administer the tests. In all schools in Iran, teaching of phonological reading to the first graders begins from the second month of the academic year. During the first month, the major focus of the educational instruction is on developing a good teacher-students relationship, strengthening grammar skills, and making children familiar with formal educational settings, such as classroom environment and school rules. Children work on a student book (Let's read), which includes 10 images (colorful fiction images) associated with children's poetry and stories. The school teacher encourages children to read in a group. This makes children learn the written form and meaning of some words from the images given in the book.

In the present study, the difference between the 2 groups (control and experimental groups) was that the intervention group received intensive instruction based on the conventional methods, meaning that they received this instruction about a month earlier than the usual time that the instruction was supposed to be given while the control group went through the conventional teaching phases according to the guidelines of the national curriculum. The intervention sessions were monitored on a weekly basis to ensure that all children received the same treatment. Briefing sessions were also held for both teachers and the team of researchers to make the treatment identical across schools.

Due to ethical considerations, all participants and their parents/caregivers were informed of the reason for exclusion and, if needed, they received necessary counseling. All tests and intervention sessions were conducted at school. The pretest was performed before mid-September 2016, while the posttest was conducted at the first week of November 2016.

All tests were repeated immediately after the end of the intervention period, ultimately within 1 week of the final intervention session. To prevent the influence of the conventional teaching schedule, the posttest was given in the first week of November because the formal instruction to teach reading for children at the first grade begins from the second month of the academic year. Academic year in Iran begins in the beginning of autumn.

\section{Statistical analysis}

Both descriptive and analytic statistics were used for data analysis. Mean and standard deviation indexes were used for representing quantitative variables and frequency index for representing qualitative variables. Also, to compare the mean of quantitative outcomes between the 2 groups, independent sample $t$ test and Mann-Whitney nonparametric tests were used. To compare pre- and posttreatment outcomes, within groups conditions, dependent $t$ test, and Wilcoxon were adopted. Xi-2 test was also used to compare qualitative factors between the 2 groups. Moreover, Pearson and Spearman tests were used to consider the correlation of variables. Data were analyzed by SPSS 22 and statistical significance was set at $\mathrm{p}<0.05$.

\section{Results}

The participants consisted of 57 healthy children (Male $=27$, Female $=35$ ) aged 66-78 months (Mean=77 \pm 4 months) living in Mashhad, Iran. There were 25 students in the intervention group (boys: 14, girls: 18) and 32 in the control group (boys: 9, girls: 16).

Table 1 demonstrates the mean scores and standard deviation (SD) for both intervention and control groups be- 
Table 1. Means and Standard deviation in the both of groups

\begin{tabular}{|c|c|c|c|c|c|c|c|}
\hline \multirow[t]{2}{*}{ Tasks } & & \multicolumn{3}{|c|}{ Intervention } & \multicolumn{3}{|c|}{ Control } \\
\hline & & Mean & SD & T-test/ Wilcoxon & Mean & $\mathrm{SD}$ & T-test/Wilcoxon \\
\hline \multirow{2}{*}{ Alliteration (10) } & Pre & 7.4 & 1.7 & $0.02 *$ & 7.5 & 1.5 & $<0.001 * *$ \\
\hline & Post & 8.4 & 1.5 & & 8.6 & 1.4 & \\
\hline \multirow[t]{2}{*}{ Rhyme (10) } & Pre & 6.4 & 2.1 & $<0.001 * *$ & 6.9 & 1.6 & $<0.001 * *$ \\
\hline & Post & 7.7 & 1.5 & & 7.7 & 1.5 & \\
\hline \multirow{2}{*}{ blending phonemes (10) } & Pre & 6.1 & 2.4 & $<0.001 * *$ & 6.8 & 2.1 & 0.3 \\
\hline & Post & 7.6 & 1.8 & & 7.0 & 1.7 & \\
\hline identification of words with the same & Pre & 6.1 & 1.5 & 0.3 & 5.6 & 1.7 & $<0.001 * *$ \\
\hline initial phoneme (10) & Post & 6.6 & 1.6 & & 6.5 & 1.8 & \\
\hline identification of words with the same & Pre & 5.3 & 2.0 & $0.05 *$ & 5.6 & 2.0 & 0.2 \\
\hline final phoneme (10) & Post & 6.2 & 2.0 & & 6.0 & 1.8 & \\
\hline Naming and deletion of final phoneme & Pre & 3.1 & 2.7 & $<0.001 * *$ & 4.4 & 2.6 & 0.5 \\
\hline (10) & Post & 5.0 & 1.9 & & 4.6 & 2.1 & \\
\hline \multirow[t]{2}{*}{ RAN (digits) (s) } & Pre & 85 & 19.9 & $0.01 *$ & 81. & 18.9 & 0.16 \\
\hline & Post & 72.4 & 17.7 & & 78.7 & 22.3 & \\
\hline \multirow[t]{2}{*}{ RAN (pictures) (s) } & Pre & 77.6 & 24.3 & $0.01 *$ & 68.6 & 20.5 & 0.4 \\
\hline & Post & 66.4 & 19.3 & & 67.0 & 22.9 & \\
\hline
\end{tabular}

* Significant with p-value less than 0.05

** Significant with p-value less than 0.01

Table 2. Correlation between PA and RAN different variables

\begin{tabular}{|c|c|c|c|c|}
\hline \multirow[t]{2}{*}{ PA Variables } & \multicolumn{2}{|c|}{ RAN (Pic) } & \multicolumn{2}{|c|}{ RAN ( Dig) } \\
\hline & Correlation & $\mathrm{p}$ & Correlation & $\mathrm{p}$ \\
\hline Alliteration (A) & -0.03 & 0.82 & 0.15 & 0.24 \\
\hline Rhyme (R) & -0.15 & 0.24 & 0.03 & 0.81 \\
\hline Blending Phonemes (B Ph) & $-0.49^{* *}$ & $<0.001$ & $-0.45^{* *}$ & $<0.001$ \\
\hline Identification of words with the same Initial phoneme (I I) & $-0.40^{* *}$ & $<0.001$ & -0.16 & 0.22 \\
\hline Identification of words with the same Final phoneme (I F) & $-0.32^{*}$ & 0.01 & $-0.26^{*}$ & 0.04 \\
\hline Naming and Deletion of Final Phoneme (N \& D F Ph) & $-0.38^{* *}$ & $<0.001$ & $-0.34^{* *}$ & $<0.001$ \\
\hline
\end{tabular}

Naming and Deletion of Final Phoneme (N \& D F Ph)

* Significant with p-value less than 0.05

** Significant with p-value less than 0.01

fore and after intervention.

As presented in Table 1, the distribution indicators showed some strains in rapid naming of numbers. In Shapiro-Wilk normality test, only the variable of "word recognition with the identical initial phoneme" was normally distributed.

A moderate correlation was observed for the 3 variables (phonemic composition, naming and deleting the last phoneme, recognizing words with identical final phoneme) between PA and RAN before the intervention (both groups included) $(\mathrm{p}<0.05)$, with two subtests of rapid naming (Table 2, Fig. 2). Furthermore, the correlation between the 2 variables of recognizing words with identical initial phoneme and rapid images naming was significant $(\mathrm{p} \leq 0.001)$.

In the intervention group, all variables related to phonological awareness, except for identifying words with identical initial phoneme, were significantly improved (Table 1). In the control group, as expected, 3 variables of phonological awareness showed no significant difference. However, alliteration, rhyme, and recognizing words with identical initial phoneme showed significant improvement after intervention.

According to the results (Table 1), in the intervention

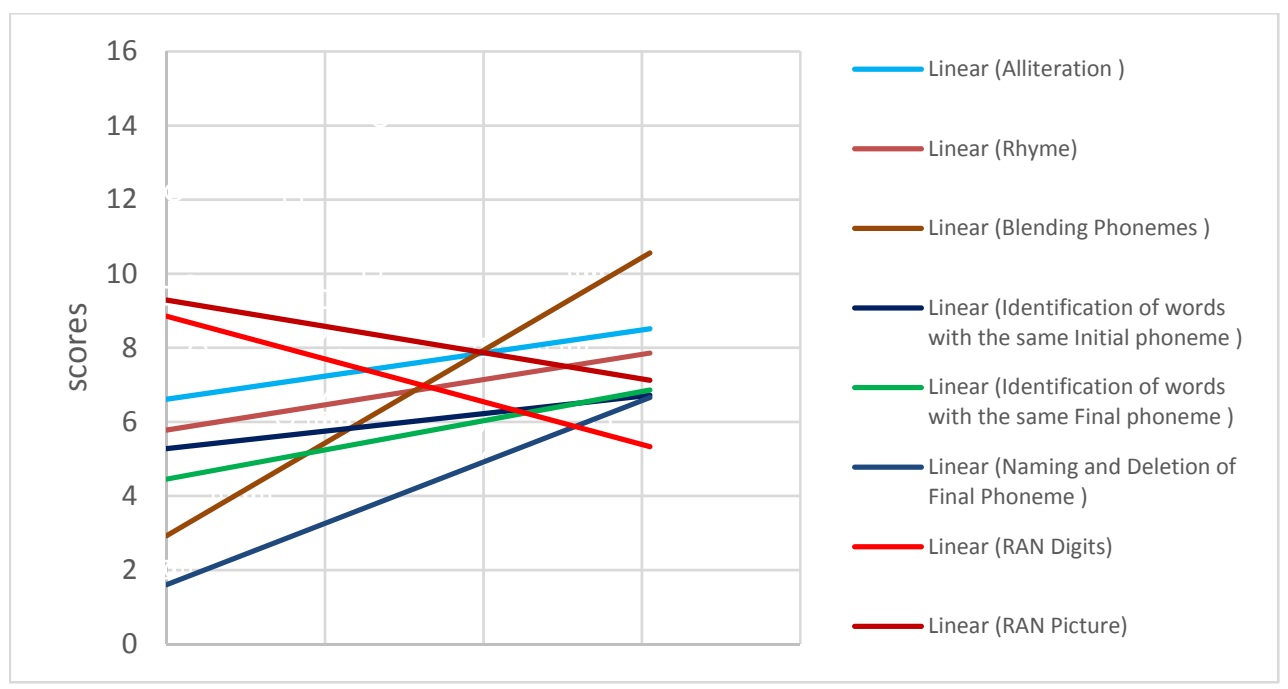

Fig. 2. Scatter plots with the fit line (Corrolation between Rapid Automatized Naming \& Phonological Awareness) 
group, the length of time for naming the numbers and the objects' images significantly decreased. However, in the control group, a decrease in the naming time was observed, which was not statistically significant.

\section{Discussion}

In this study, the effect of intervention in phonological awareness on rapid automatized naming (RAN) in healthy children was studied to further provide evidence whether rapid naming and phonological awareness should be considered as independent predictors of reading acquisition to better identify those at risk. The results showed that a significant increase in performance of phonological awareness in healthy children was associated with a significant increase in rapid automatized naming. In addition, a moderate relationship was observed between some components of phonological awareness and rapid automatized naming.

Although the correlation between rapid naming and PA has been examined in many studies, their results have not resolved the dispute among researchers. In some studies, the levels of such correlation have been reported to range from moderate to high $(40,41)$. Such correlation indicates that rapid naming as an underlying path of reading is mediated through phonological awareness. In contrast, some other researchers have reported such correlation to range from low to moderate, considering rapid naming as a component skill of phonological awareness that has a distinct role than that of PA, which can also influence forming orthographic representations (42).

\section{Variables changes in control group}

The results demonstrated that children's abilities in the control group were significantly increased on congenital diagnosis, rhythmic diagnosis, and recognition of words with the same initial phonemes. It is interesting to tap into the underlying reasons as why such a change has occurred and why such changes did not affect the RAN scores. Since neither intensive training occurred at home (based on parents' interviews), nor outliers who could affect the mean scores were found, this finding may suggest 2 interpretations: (1) development of language skills due to the exposure to a richer environment; and (2) effects of formal education during the first month of schooling. The possibility that parents might have trained their children at home was ruled out, as all parents were contacted and asked if they had any trainings with their children at home.

Given that the phonological tasks that children in this study went through were simple for their age group, such improvements can be expected due to the evolutionary stage or natural cognitive development that children at this age may go through. Additionally, the effect of the teaching method at the first month of schooling, which emphasizes reciting poems, can be influential.

\section{Why RAN changed in the intervention group}

The results demonstrated a significant correlation between PA and RAN in phonemic blending. Alliteration and rhyme detection had no significant relationship with RAN. Considering the significant improvement in rhythm and alliteration scores in both groups, but their low correlation with RAN, it can be interpreted that alliteration and rhythm are neutral skills.

Three subskills, including phonemic blending, word identification with the same final phoneme, and naming and deleting final phonemes, had moderate to high correlations with RAN. Elision and phoneme blending have been used to measure phonological awareness (44-47). Lovet also developed a phonological awareness training program targeting children with phonological deficits based on phonemic blending and elision exercises (45). Wolf and Bower implemented phonological blending and elision tasks among 3 groups of children who were either identified with deficits in phonological awareness, deficits in RAN, and deficits in both PA and RAN to examine the underlying skills related to phoneme blending and phoneme elision. They found that elision and phoneme blending did not predict deficits in naming speed in the group identified with RAN deficits.

Phonemic blending and elision (in the process of speech and language development) have been reported as the basic skills to identify a written word. Hence, it can be argued that using such screening tests among preschool children may help to identify those at risk before they fail in their reading acquisition (48-49). It is also believed that rhyme prepares children for the next step in their speech and language development, which is phoneme blending.

Wagner (48) proposed 2 models for preschool and elementary school-age children. He reported relatively high correlations between rapid naming of numbers and phonological awareness with phoneme blending and phoneme elision. In addition, Wagner believed that while phoneme blending and elision are components of the phonological awareness assessment battery, they tap into different underlying skills. Phonemic blending, as Wagner argues, taps into rapid naming while phoneme elision taps into working memory. Therefore, considering Wagner's argument, perhaps the reason for observing a higher correlation between phonemic blending and RAN may attribute to their reference to a latent underlying variable.

The results of the present study, consistent with previous published research, reflected the impact of phonological awareness training on rapid naming. Correlations between the 2 groups (control and experimental groups), the intervention program, blending exercises, recognizing the initial and final phonemes, and phonological deletion might have had the greatest impact on increasing the performance of rapid naming. In the control group, the scores of rhyme and alliteration have shown improvement, but this progress did not lead to a significant increase in the performance of rapid naming.

One limitation in this study was the lack of access to a larger sample of all public schools. Further evidence of the variables affecting the efficiency of early and preventive intervention may be obtained by repeating this study with a larger sample size and classifying the samples (normal growth of reading and dyslexia). In addition, we could not apply a reliable test to predict the possibility of 
learning disability in participants. Also, we did not match the participants based on their IQ scores.

\section{Conclusion}

The results of this study demonstrated that intervention in basic skills of phonological awareness in healthy children could positively affect rapid naming performance in subtests of numbers and images. These findings, along with the moderate correlation of phonological blending, deleting and recognition with rapid automatized naming, do not support the underlying independence of the rapid automatized naming and phonological awareness. Thus, it is suggested that this study be replicated in a longitudinal study and with a larger sample size.

\section{Acknowledgements}

The research was implemented as a master's thesis and with the financial support of Iran University of Medical Sciences (number: 9411360004). This article utilized the data from the thesis of Mahdi Khodadoust, a graduate student at Iran University of Medical Sciences, supervised by Dr. Reyhane Mohamadi and Dr. Amir Sadeghi.

IRCT Registration Code: IRCT2016101230273N1.

\section{Conflict of Interests}

The authors declare that they have no competing interests.

\section{References}

1. Buscher C. Effect of an Intensive Intervention on the Early Literacy Skills of Kindergarten Students Identified as Most at Risk for Future Reading Difficulties. 2014, University of Montana. p. 180.

2. Thomson M. Developmental dyslexia. Vol. 7. 1990 John Wiley \& Sons Incorporated.

3. Rayner K, Pollatsek A. The psychology of reading. 1995: Erlbaum.

4. Snowling, M.J., Early identification and interventions for dyslexia: a contemporary view. J Res Spec Educ Needs. 2013;13(1):7-14.

5. Lipson M, Wixson K. Assessment and instruction of reading and writing disability. NY: Longman, 1997.

6. Joshi RM, Tao S, Aaron PG, Quiroz B. Cognitive component of componential model of reading applied to different orthographies. J Learn Disabil. 2012;45(5):480-486.

7. Scarborough HS. Antecedents to reading disability: Preschool language development and literacy experiences of children from dyslexic families, in Reading Disabilities. 1991, Springer. p. 31-45.

8. Snowling M. dyslexia. 2 ed. 2000: Wiley-Blackwell.

9. Thompson, P.A., et al., Developmental dyslexia: predicting individual risk. J. Child Psychol. Psychiatry. 2015;56(9):976-987.

10. Stanovich KE. Explaining the differences between the dyslexic and the garden-variety poor reader: The phonological-core variabledifference model. J Learn Disabil. 1988;21(10):590-604.

11. Wagner RK, Torgesen JK. The nature of phonological processing and its causal role in the acquisition of reading skills. Psychol Bullet. 1987;101(2):192.

12. Seki A, Kassai K, Uchiyama H, Koeda T. Reading ability and phonological awareness in Japanese children with dyslexia. Brain Dev. 2008;30(3):179-188.

13. Torgesen JK. The prevention of reading difficulties. J Educ Psychol. 2002;40(1):7-26.

14. Vukovic RK, Siegel LS. The double-deficit hypothesis: A comprehensive analysis of the evidence. J Learn Disabil. 2006;39(1):25-47.

15. Wolf M, Bowers PG. The double-deficit hypothesis for the developmental dyslexias. J Educ Psychol. 1999;1(3): 415.

16. Wagner RK, Torgesen JK, Laughon P, Simmons K, Rashotte CA. Development of young readers' phonological processing abilities. J Educ Psychol. 1993;85(1):83.

17. Wolf M, O'rourke AG, Gidney C, Lovett M, Cirino P, Morris R.
The second deficit: An investigation of the independence of phonological and naming-speed deficits in developmental dyslexia. Read Writ. 2002;15(1):43-72.

18. Meyer MS, Wood FB, Hart LA, Felton RH. Selective predictive value of rapid automatized naming in poor readers. J Learn Disabil. 1998;31(2):106-117.

19. Wolf M. Naming speed and reading: The contribution of the cognitive neurosciences. Read Res Q. 1991: 123-41.

20. Papadopoulos TC, Spanoudis GC, Georgiou GK. How Is RAN Related to Reading Fluency? A Comprehensive Examination of the Prominent Theoretical Accounts. Front Psychol. 2016;7(1217).

21. Schatschneider C, Carlson CD, Francis DJ, Foorman BR, Fletcher JM. Relationship of rapid automatized naming and phonological awareness in early reading development: Implications for the doubledeficit hypothesis. J Learn Disabil. 2002;35(3):245-256.

22. Chiappe P, Stringer R, Siegel LS, Stanovich KE. Why the timing deficit hypothesis does not explain reading disability in adults. Read Writ. 2002;15(1):73-107.

23. Sunseth K, Greig Bowers P. Rapid naming and phonemic awareness: Contributions to reading, spelling, and orthographic knowledge. J Res Read. 2002;6(4):401-429.

24. Heikkilä R, Torppa M, Aro M, Närhi V, Ahonen T. Double-deficit hypothesis in a clinical sample: Extension beyond reading. J Learn Disabil. 2016. 49(5):546-560

25. Wanzek J, Vaughn SResearch-based implications from extensive early reading interventions. Sch. Psychol. Rev. 2007;36(4): 541.

26. Wanzek J, Vaughn S, Scammacca N, Metz K, Murray C, Roberts G, et al. Extensive reading interventions for older struggling readers: Implications from research. Rev Educ Res. 2013;83:163-195.

27. Ozernov-Palchik O, Norton ES, Sideridis G, Beach SD, Wolf M, et al. Longitudinal stability of pre-reading skill profiles of kindergarten children: implications for early screening and theories of reading. Dev Sci. 2017 Sep;20(5):e12471.

28. Lovett MW, Steinbach KA, Frijters JC. Remediating the core deficits of developmental reading disability A double-deficit perspective. J Learn Disabil. 2000;33(4):334-358.

29. Nelson JM. Examination of the double-deficit hypothesis with adolescents and young adults with dyslexia. Ann Dyslexia. 2015;65(3):159-177

30. Farabi M, Bayazi MH, Teymori S. Impact of phonological awareness training on reading skills in students suspected as dislexic. Iran J Except Child. 2010;10(4):335-342.

31. Baluch B. Persian Orthography and Its Relation to Literacy. 1 ed: Middlesex University; 2005.

32. Dastjerdikazemi M, Soleimani Z. Phonological Awareness Test. 2003.

33. Denckla MB, Rudel R. Rapid “automatized 'haming of pictured objects, colors, letters and numbers by normal children. Cortex. 1974;10(2):186-202.

34. Plaza M, Cohen H. Predictive influence of phonological processing, morphological/syntactic skill, and naming speed on spelling performance. Brain Cogn. 2004;55(2):368-373.

35. Mikaielimonie F, Farahani M. Phonological processing model of reading in male normal and dyslexic student. Research on Exceptional Children. Winter 2006;18(2):7-14.

36. Soleymani Z, Barkhordar A, Moradi A, Jalaee S. Designing and measuring the validity and reliability of rapid automatized naming test in the first-grade students. Modernn Rehabil. 2007;1(2):1-6.

37. Sima-Shirazi T, Nili-Pour R. Diagnostic Reading Test. 2004

38. Sima-Shirazi T, Nili-Pour R. Developing and Standardization of a Diagnostic Reading Test. Arch Rehabil. 2004;5(1 and 2):7-11.

39. Nematzade SH, Dadras M, Dastjerdi Kazemi M, Mansousrizade M. Persian core vocabulary based on Iranian children. 2011, Tehran: Madreseh.

40. Torgesen JK, Wagner RK, Rashotte CA, Burgess S, Hecht S. Contributions of phonological awareness and rapid automatic naming ability to the growth of word-reading skills in second-to fifth-grade children. Sci Stud Read 1997;1(2):161-85.

41. Wagner RK, Torgesen JK, Rashotte CA. Development of readingrelated phonological processing abilities: New evidence of bidirectional causality from a latent variable longitudinal study. Dev Psychol. 1994;30(1):73.

42. Furnes B, Samuelsson S. Phonological awareness and rapid automatized naming predicting early development in reading and spelling: Results from a cross-linguistic longitudinal study. Learn Individ Dif- 
fer. 2011;21(1):85-95

43. Wimmer H, Mayringer H, Landerl K. Poor reading: A deficit in skill-automatization or a phonological deficit?. Sci Stud Read. 1998 Oct 1;2(4):321-40.

44. Goldberg A, Wolf M, Cirino P, Morris R, Lovett M. A test of the double-deficit hypothesis. in annual meeting of the Society for the Scientific Study of Reading, San Diego, CA. 1998.

45. Lovett MW, Steinbach KA, Frijters JC. Remediating the core deficits of developmental reading disability A double-deficit perspective. J Learn Disabil. 2000;33(4):334-358.

46. Wolf M, Bowers PG. The double-deficit hypothesis for the developmental dyslexias. J Educ Psychol. 1999;91(3):415.

47. Gidney C, Deeney T, Wolf M, Holmes J, Cirino P, Morris R. The presence of phonological and naming-speed deficits in AfricaAmerican children. in Poster presented at the Conference on Language Development in African-American Children. Memphis, TN. 1998.

48. Wagner RK, Torgesen JK, Laughon P, Simmons K, Rashotte CA. Development of young readers' phonological processing abilities. J Educ Psychol. 1993;85(1):83.

49. Papadopoulos TC, Spanoudis GC, Georgiou GK. How Is RAN Related to Reading Fluency? A Comprehensive Examination of the Prominent Theoretical Accounts. Front Psychol. 2016;7(1217). 